\title{
THE RELATIONSHIP BETWEEN HEALTH LOCUS OF CONTROL, DEPRESSION, AND SOCIODEMOGRAPHIC FACTORS AND AMOUNT OF TIME BREAST CANCER PATIENTS WAIT BEFORE SEEKING DIAGNOSIS AND TREATMENT
}

\author{
Inga Marijanović1 , Gordana Pavleković ${ }^{2}$, Teo Buhovac ${ }^{1} \&$ Marko Martinac ${ }^{3}$ \\ ${ }^{1}$ Oncology Clinic, University Clinical Hospital Mostar, Mostar, Bosnia and Herzegovina \\ ${ }^{2}$ Department for Social Medicine and Organization of Health Care, University of Zagreb, School of Medicine, \\ Andrija Stampar School of Public Health, Zagreb, Croatia \\ ${ }^{3}$ Center for Mental Health, Mostar Health Center, Mostar, Bosnia and Herzegovina
}

received: 14.6.2016;

revised: 15.2.2017;

accepted: 20.3.2017

\section{SUMMARY}

Background: In the Federation of Bosnia and Herzegovina, the prevalence and incidence of breast cancer has been increasing, and the national programme of early prevention, administered locally, is sporadic and without quality assurance. While many factors may influence women's decision to adopt prevention-oriented behaviours regarding breast cancer, this study has emphasised the importance of sociodemographic factors, psychological factors and mental wellbeing.

Subjects and methods: Participants in the study were all patients who, during one year, were admitted for the first time for diagnosis and treatment in the biggest Clinical hospitals of the Herzegovina-Neretva region Patients were divided into two groups based on their TNM classification: "early stage" and "late stage". Three instruments were used in this study: an individual questionnaire about demographic and socioeconomic characteristics of the woman, the Multidimensional Health Locus of Control scales, and the Hamilton Depression Rating Scale

Results: The majority of patients diagnosed with advanced disease were admitted to hospital in the late/advanced stages of the disease. Multi-variant analysis showed that the most statistically significant positive predictor for early admittance in hospital is living with family and marital status while religiosity has a negative predictive value. The results indicate that 59.7\% of respondents do not have depression, while the remainder do have some degree of depression. There was no statistically significant difference in the degree of depression between women who were diagnosed and treated early and those who were not. The employment status of the respondents was the only significant factor related to degree of depression.

Conclusion: Although health locus of control and depression are not statistically significant predictors of early hospital treatment, the recommendation is that further studies focus on the implementation of MHLC and HDRS scales within the community. This could be useful in planning appropriate and specific interventions, not only because of early diagnosis, but also to ensure good mental health and resilient behaviour.

Key words: health locus of control - depression - sociodemographic factors - breast cancer

\section{INTRODUCTION}

Breast cancer, the most common form of cancer among women in developed and developing countries, is one of the leading public health concerns due to its high prevalence and incidence, treatment and rehabilitation costs, as well as the decrease in quality of life of the patient. The International Agency for Research on Cancer (IARC) claims that new incidents of cancer in 2012 increased to 14.1 million, with 8.2 million deaths (IARC 2014). According to the IARC, cancer incidence will increase up to 19.3 million by 2025 , to 22 million by 2030, and even up to 24 million by the year 2035. In developed countries (excluding Japan) incidence rates are high, while developing countries report lower incidence. However, due to social and economic transitions in developing countries, the rate of growth is higher, which is related to lifestyle changes as well as late diagnosis and treatment. In
Europe, more than one quarter $(25.5 \%)$ of newly diagnosed cases of cancer in women are cases of breast cancer, and the mortality rate among them is $17.5 \%$. According to epidemiological data, $81 \%$ of newly diagnosed breast cancer cases are in the early stages and $19 \%$ in advanced stages. In the last 25 years, the rate of incidence has increased in developed countries by $30 \%$, which can be explained partly by better diagnosis through organized programs of early detection (Bray et al. 2013, Stewart \& Wild 2014).

The leading causes of mortality among the population of the Federation of Bosnia and Herzegovina (FB\&H) in 2013 are cardiovascular disease (52.9\%) and malignant neoplasm $(21.5 \%)$, the rates of which are increasing moderately (Public Health Institute of the FB\&H 2013). In its report on chronic, noncommunicable disease, the World Health Organization states that only a population cancer registry can provide reliable data on the prevalence and incidence of 
malignant neoplasms among the population (WHO 2002, WHO 2008). Public Health Institute of FB\&H initiated a procedure to establish a cancer registry, with the goal of registering all cases of cancer within the Federation. The registration process has been decentralized: primary, secondary and tertiary healthcare services, as well as the private healthcare sector, report cancer cases to the cantonal institutes for public health, which are delivered to the Public Health Institute of the FB\&H, where the data are combined. Imprecise instructions and the inadequate education of healthcare practitioners results in the under-registration of new cases of cancer, as well as a relatively low quality of data. According to indicators published in 2013, the incidences of cancer are 229/100.000 among men and 210/100.000 among women (Public Health Institute of the FB\&H 2013). The most common type of cancer among women is breast cancer (55-65/100.000 women). According to a report by GLOBOCAN, in Bosnia and Herzegovina, 1,622 new cases of breast cancer can be expected, with an incidence of 79.2/100,000 and with the average age of incidence at 58.9 (Ferlay et al. 2012). It is estimated that 600 women within the Federation die each year, with a mortality rate of 29.3/100,000.

More than $90 \%$ of breast cancer cases are curable if the diagnosis is established in early stages and if proper treatment is administered. Mammography is the gold standard in cancer detection, and the most important screening method (Gabe \& Duffy 2005). The World Health Organization recommends that mammography be administered on a national scale, because experiences worldwide demonstrate that individual efforts by communities, organizations, clinics, etc. are not as efficient as those conducted at a national level (WHO 2002). The experiences of neighbouring states (e.g. the Republic of Croatia) demonstrate that legislative documents (strategy, program, register) facilitate early breast cancer diagnosis and treatment (Ministry of Health and Social Welfare, Republic of Croatia 2011). At the same time, these experiences highlight the problem of women's attitudes towards mammography as a reliable choice for early detection, which can be used as a predictor for late diagnosis and treatment.

Research into the causes of late diagnosis and treatment of women with breast cancer indicate that it is a complex question which is researched in a social, economic and psychological, as well as cultural context. The most common reasons for the delayed initial consultation regarding diagnosis and treatment are advanced age, low socio-economic status, level of formal education, unemployment, marital status, as well as inaccessibility to mammography within a reasonable distance (Banks et al. 2002, Polašek et al. 2007). However, the research is inconclusive. For example, in numerous studies advanced age is related to failure to attend at the diagnostic centre for tests, but other research indicates the opposite (Celaya et al. 2010).
Different studies have different results related to accessibility (e.g. distance to the center for mammographic screening, whether the service is free or paid). Most studies indicate an inverse correlation between level of education and breast cancer risk factors. In most studies, high socioeconomic status is related to a high level of education as well as better health conditions (Lantz et al. 1997, Ramirez et al. 1999, Moore 2006). Highly educated women are better informed about breast cancer (the disease itself as well as treatment options). Employed women most likely respond to organized screening due to encouragement in the workplace from female coworkers, but it is also possible that this is the result of better socioeconomic status and higher family income. The effect of marital status on the diagnosis, treatment, and survival rate of cancer patients has been confirmed in numerous studies (Neale et al. 1986, Goodwin et al. 1987, James \& Anderson 1999, Ayal et al. 2013). Unmarried women tend to live shorter once diagnosed.

The relationship between socioeconomic status (SES) and breast cancer is complex (Badur et al. 2014). The rate of incidence increases with an increase in SES. However, the incidence of metastasized breast cancer is higher among women of a lower SES. This discrepancy coincides with the report that women with a high SES have a lower response to mammography screening and a lower rate of follow-up appointments in the recommended period after an abnormal mammogram. Women of a lower SES more often ignore symptoms and fail to understand the elements of progression of the disease and are more likely to be diagnosed in later stages of the disease (Atndt et al. 2001, Downing et al. 2007, Schueler et al. 2008). Encouragement from social support networks and place of residence are also connected with attending at routine screenings. Research conducted by Polašek et al. in the Republic of Croatia indicates that rural environment is an important factor in the response to appeals to attend at screening sessions, even when SES and accessibility factors are controlled for. The same authors note that accessibility to healthcare is the strongest predictor of screening (Polašek et al. 2007). Other authors have also found differences for attending at screenings between rural and urban settings (Stamenić \& Strnad 2011, Schueler et al. 2008). Psychosocial determinants, such as attitudes towards health and disease and/or early detection of disease are related to the health behaviour of individuals and, in accordance with this, to attendance at screenings and early treatment (Forbes et al. 2013). Norsa'adah et al. showed that the main barriers were poor knowledge or awareness of breast cancer, fear of cancer consequences, other priorities, denial of disease and health care system weakness. They concluded that healp-seeking behaviour is influenced by a complex interaction of cognitive, environmental, beliefs, culture and psycho-social factors (Norsa'adah et al. 2012). 
This research stems from two problems:

The first is related to the specific situation in Federation of Bosnia and Herzegovina, a state in a long-term political, economic, and social transition. The long-term transition has directly caused the deterioration of the SES of citizens, and the latest available data from surveys measuring the standard of living (LSMS) demonstrate that approximately $15 \%$ of the population of FB\&H live below the poverty line (Institute for Statistics FB\&H 2014). The situation in the HercegovinaNeretva region, in which this research was conducted, is similar. According to data from 2012, this region has 224,652 inhabitants (with 123, 327 women), and the economic situation has resulted in the population gap. The agricultural sector has taken over the role of social stabilizer for the most vulnerable part of the population. These are mostly households that usually focus on food production for personal needs and the part of the population who are capable of working but are unemployed due to the collapse of the industrial sector. The transition has had an impact on the healthcare system, which includes, among other things, organization and implementation of cancer prevention programs (Public Health Institute of the FB\&H, 2013). In the region where the research was conducted, the leading cause of mortality among men is lung cancer (33.9\%) and breast cancer among women (14.9\%). The majority of women with breast cancer living in this region seek treatment in the Oncology clinic at the University Hospital in Mostar, which is the political, economic, scientific, and cultural centre of the entire region. According to hospital record data, 619 women were treated for breast cancer in 2011, and 463 in 2012. The early detection program has been implemented in a similar manner as in the Federation, and has been ameliorated by the purchase of mammography machines, which are located in four out of nine municipalities within the region. The activities are being implemented in coordination with the healthcare services and civil society. However, the activities are sporadic and uncoordinated in local communities, and there are no follow-up assessments of their effectiveness. Because of this, there are no evidence-based indices about the attendance at mammography screenings, and the only available data are those provided by the oncology clinic, which are about women seeking treatment at different stages of the disease. Therefore, the problem faced by this study is to determine which factors within this contextual framework contribute to early or late admittance at hospital by women for diagnostic or therapeutic purposes.

The second problem is related to the psychosocial profile of individuals who delay in admittance to hospital for breast cancer diagnosis and treatment. While many factors may influence women's decision, researchers have emphasised the importance of individual responsibility. There are numerous theoretical models concerned with the psychosocial profile of individuals who are proactive about their health (Forbes et al.
2014). According the health locus of control model, individuals with an internal locus of control are more likely to respond to calls for routine screenings (Holm et al. 1999). The belief that an individual cannot change her destiny (the extreme end of the external locus of control spectrum, i.e. a fatalistic mentality) can contribute to a reduced likelihood of responding to calls for routine screenings and an increased likelihood of delaying the seeking of treatment. The Multidimensional Health Locus of Control Scale (MHLC), developed by Wallston, Wallston and DeVellis in 1978, was often used in the available literature (Wallston et al. 1978, Wallston et al. 2005). Since its development, the MHLC scale has been evaluated in numerous studies of health behaviour. Some studies supported that the MHLC was a valuable predictor of health behaviour while others did not. The challenge of this study is in determining whether it is the health locus of control which predicts the early or delayed seeking of diagnosis and treatment at hospital or whether other, previously stated predictors have a stronger impact.

Research indicates that psychological distress is often present in those suffering from malignant disease. The diagnosis and treatment of breast cancer evokes emotional trauma as well as physiological distress (Massi 2004, Gili et al. 2010, Kissane et al. 2011, Tojal \& Costa 2015). Emotional trauma can lead to increased emotional fragility, loss of control, and uncertainty. The diagnosis of malignant disease evokes more intense emotional reactions than any other disease, so the moment they are diagnosed a set of defense mechanisms are activated in order to maintain emotional balance. In his review, Aukst-Margetic et al. warn that depression is common among oncology patients, but underreported (Aukst-Margetić et al. 2002). Research estimates that the prevalence of depression among oncology patients fulfills the criteria for Major Depression is between 20-25\% patients (Ballenger et al. 2001). According to Sellick \& Crooks the prevalence of depression and anxiety among patients is is $25-40 \%$ during the first year of diagnosis, which considerably affects their quality of life (Sellick \& Crooks 1999). Burgess' study indicate that the incidence of depression in women who have been diagnosed with cancer is $33 \%$ during diagnosis, $15 \%$ one year after the diagnosis, and $45 \%$ after recurrence (Burgess et al. 2005). According to a Danish study of breast cancer patients, independent risk factors for depressive episodes include young age, social status, comorbidity, history of psychiatric illness, poor body functioning, smoking, alcohol use, and BMI (Christiansen et al. 2009). Additionally, it is established that patients with depression have a significantly lower health utility value than those without depression, which could have an effect on the early seeking of diagnosis and the early recognition of symptoms (Fujisawa et al. 2016). In short, although research data on the prevalence of depression among women suffering from 
breast cancer vary, and the relationship with sociodemographic factors is different, it could be assumed that depression is one of the more important factors affecting the early diagnosis, coping with the disease, and quality of life.

According to the described problems, the aim of this study is to examine the relationship between health locus of control, degree of depression, and sociodemographic factors and the amount of time breast cancer patients wait before seeking diagnosis and treatment.

\section{SUBJECTS AND METHODS}

This study was conducted from January to December 2014 at the Oncology Clinic at the University Hospital in Mostar in the Herzegovina-Neretva region of the Federation of Bosnia and Herzegovina. During that period, 403 subjects were admitted for initial diagnosis and treatment, and the majority of them (305, or $75.7 \%$ ) were at the later stages of the disease. The classification of the disease is established according to the TNM classification, and for our study 'early stage' is stage I (i.e. T1N0M0) and the 'late stage' ranges from stage II, III, and IV (International Agency for Research on Cancer 2012). Data regarding the stage of the disease according to the TNM classification of breast cancer were obtained from hospital records.

Instruments used in the study were:

- A specially-designed individual questionnaire based on international experiences, especially based on previously developed, valid questionnaires, used in the national program of early breast cancer detection in the Republic of Croatia. The content of the questionnaire was appropriate for the research aim and objectives, and contained demographic, socioeconomic and other individual characteristics of the subjects.

- The MHLC scale was translated from English to Croatian language (the language used in the region) using simultaneous translations and blind backtranslations followed by group consultation with bilingual experts. The MHLC scales containing 36 questions (claims) to which the subjects must respond on a scale from 1 - strongly disagree to $6-$ strongly agree. The MHLC scales consist of three forms (A, B and C). A and B are parallel forms and either one can be used, while form $\mathrm{C}$ is applied for either the sick or to measure health locus of control under special conditions (Wallston et al. 1978). The results indicate that if the person has an internal health locus of control (or to what extent one believes her behaviour and internal factors are responsible for health and sickness), powerful others locus of control shows to what extent one believes others determine her health, and chance locus of control shows to what degree one believes that health depends on chance.
- The degree of depression is measured using the Hamilton Depression Rating Scale (HDRS), one of the most commonly used measures of depression, which has been in use since 1960 (Hamilton 1960, Williams 2001, Shafter 2006). The scale exists in two versions: a 17-item scale which determines the total score and the degree of depression, and an additional 4-item scale (18-21) which is used to further qualify the depression. The shorter, 17-item version, is used more often and was therefore used in this research. In cases of mild depression, the total number of points on the HDRS-17 does not exceed 18; in moderate depression the total number is between 18 and 25, and in severe depression the number is greater than 25 .

Ethical approval was received from the Ethics Committee of the University Hospital and all ethical principles were respected. Participants were made familiar with the goals and purpose of the research and gave informed consent to participate in the study.

Statistical calculations were performed using SPSS for Windows and Microsoft Excel (version 17.0, SPSS Inc, Chicago, Illinois, USA). Standard methods of descriptive statistics were used in the statistical analysis of the data. Parametric and non-parametric tests were used for the analysis of the statistical significance of the differences among the samples. The non-parametric Sperman test, the Pearson correlation test and a multivariant variance analysis for standard regression analysis (ANOVA) (linear and logistic regression analysis) were used for multivariant correlation analysis. Multivariant regression analysis was used for dichotomous dependent variables. A p-value of $<0.05$ was used for the testing of the hypothesis.

\section{RESULTS}

\section{Socio-economic variables and time to admission to hospital}

The median age of the 403 research subjects was 61 years. Half of participants live in the city (51.6\%), 46 $(11.4 \%)$ in the suburbs, and $46(37 \%)$ in rural areas. The majority are married $(281$, or $69.7 \%)$ and live with their families $(336$, or $83.4 \%$ ), with a relatively decent monthly income $(267$, or $66.2 \%$ with earnings greater than 300 BAM). The majority of subjects have completed high school $(45.7 \%)$ or elementary school $(32 \%) .185$ (or $45.9 \%$ ) are retired, and there is an almost equal number of employed $(26 \%)$ as unemployed $(23.3 \%)$ subjects. The majority of subjects expressed religious beliefs, majority of them are Roman Catholic (385, or $95.5 \%)$.

According to the previously established markers, the significance of the difference between women with breast cancer who came early for diagnosis and those who came later is shown in Table 1. 
Table 1. Differences in sociodemographic variables of subjects regarding time of admission in hospital

\begin{tabular}{|c|c|c|c|c|c|c|}
\hline & \multicolumn{4}{|c|}{ Admission to hospital } & \multirow{3}{*}{$\chi^{2}$} & \multirow{3}{*}{$\mathrm{p}$} \\
\hline & \multicolumn{2}{|c|}{ Delayed } & \multicolumn{2}{|c|}{ Early } & & \\
\hline & $\mathrm{n}$ & $\%$ & $\mathrm{n}$ & $\%$ & & \\
\hline Residence & & & & & 1.641 & 0.440 \\
\hline Urban & 156 & 51.1 & 52 & 53.1 & & \\
\hline Rural & 117 & 38.4 & 32 & 32.7 & & \\
\hline Sub-urban & 32 & 10.5 & 14 & 14.3 & & \\
\hline Living condition & & & & & 2.282 & $0.328^{*}$ \\
\hline With family & 256 & 83.9 & 80 & 81.6 & & \\
\hline Living alone & 46 & 15.1 & 15 & 15.3 & & \\
\hline Others & 3 & 1.0 & 3 & 3.1 & & \\
\hline Marital status & & & & & 5.466 & 0.141 \\
\hline Married & 205 & 67.2 & 76 & 77.6 & & \\
\hline Single & 30 & 9.8 & 6 & 6.1 & & \\
\hline Widowed & 62 & 20.3 & 16 & 16.3 & & \\
\hline Divorced & 8 & 2.6 & 0 & 0.0 & & \\
\hline Education & & & & & 2.382 & 0.794 \\
\hline No qualification & 23 & 7.5 & 8 & 8.2 & & \\
\hline Primary school (8 years) & 103 & 33.8 & 26 & 26.5 & & \\
\hline Secondary school (12 years) & 135 & 44.3 & 49 & 50.0 & & \\
\hline Higher school (14 years) & 20 & 6.6 & 6 & 6.1 & & \\
\hline More than 12 years & 23 & 7.5 & 9 & 9.2 & & \\
\hline Unknown & 1 & 0.3 & 0 & 0.0 & & \\
\hline Occupation & & & & & 8.638 & 0.035 \\
\hline Employed & 72 & 23.6 & 33 & 33.7 & & \\
\hline Unemployed & 68 & 22.3 & 26 & 26.5 & & \\
\hline Retired & 147 & 48.2 & 38 & 38.8 & & \\
\hline Others & 18 & 5.9 & 1 & 1.0 & & \\
\hline Income & & & & & 4.860 & 0.182 \\
\hline Retirement & 167 & 54.8 & 44 & 44.9 & & \\
\hline Salary & 84 & 27.5 & 38 & 38.8 & & \\
\hline Social care support & 6 & 2.0 & 1 & 1.0 & & \\
\hline Others & 48 & 15.7 & 15 & 15.3 & & \\
\hline Monthly income & & & & & 1.051 & 0.591 \\
\hline Less than $150 \mathrm{KM}$ & 13 & 4.3 & 4 & 4.1 & & \\
\hline Between 150 and $300 \mathrm{KM}$ & 94 & 30.8 & 25 & 25.5 & & \\
\hline More than $300 \mathrm{KM}$ & 198 & 64.9 & 69 & 70.4 & & \\
\hline Religious & & & & & 2.174 & 0.140 \\
\hline Yes & 294 & 96.4 & 91 & 92.9 & & \\
\hline No & 11 & 3.6 & 7 & 7.1 & & \\
\hline Mammography & & & & & 4.406 & 0.036 \\
\hline Yes & 111 & 36.4 & 48 & 49.0 & & \\
\hline No & 194 & 63.6 & 50 & 51.0 & & \\
\hline
\end{tabular}

*Fisher's exact test

Those who are employed and those who have had mammograms in the past seek treatment at hospital significantly earlier. Statistically significant differences were not perceived in other variables among subject groups.

\section{Health locus of control and time to admission in hospital}

Reliability of the MHLC scales was evaluated using Cronbach's alpha test. Cronbach's alpha was 0.61 for Internal Health Locus of Control, 0.8 for Chance Health Locus of Control, 0.68 for Power Health Locus of
Control. The distribution of answers according to questions in the MHLC scale is shown in Figure 1.

The comparison among the answers of the two groups (late or early arrival at diagnosis and treatment in hospital) to each claim of the MLHC scales (form A, $\mathrm{B}$, and C) did not show statistically siginficant differencees except in three claims: "When I get sick, I am to blame" ( $p=0.041)$, "If I see an excellent doctor regularly, I am less likely to have health problems" $(p=0.043)$ and "When I feel ill, I know it is because I have not been taking care of myself properly" $(\mathrm{p}=0.033)$ (Table 2). 
Table 2. Differences in answers to claims in the MHLC scales (A, B, C) between patients with breast cancer in early and late stages of the disease

\begin{tabular}{|c|c|c|c|c|}
\hline \multirow[t]{3}{*}{ MHLC (A) } & \multicolumn{4}{|c|}{$\begin{array}{l}\text { Admission to } \\
\text { hospital }\end{array}$} \\
\hline & Early & Delayed & \multirow[t]{2}{*}{$\mathrm{t}$} & \multirow[t]{2}{*}{$\mathrm{p}$} \\
\hline & $\bar{X} \quad \mathrm{SD}$ & $\bar{X} \quad \mathrm{SD}$ & & \\
\hline If I get sick, it is my own behavior which determines how soon I get well again. & 4.561 .26 & 4.511 .37 & 0.340 & 0.734 \\
\hline No matter what I do, if I am going to get sick, I will get sick. & 4.141 .63 & 3.871 .70 & 1.402 & 0.162 \\
\hline Having regular contact with my physician is the best way for me to avoid illness. & 4.521 .37 & 4.491 .44 & 0.172 & 0.863 \\
\hline Most things that affect my health happen to me by accident. & 4.011 .54 & 3.801 .55 & 1.146 & 0.252 \\
\hline Whenever I don't feel well, I should consult a medically trained professional. & 4.231 .68 & 4.551 .51 & 0.726 & 0.085 \\
\hline I am in control of my health. & 4.151 .45 & 4.361 .36 & 1.269 & 0.205 \\
\hline My family has a lot to do with my becoming sick or staying healthy. & 3.711 .77 & 3.711 .79 & 0.014 & 0.989 \\
\hline When I get sick, I am to blame. & $2.601 .75^{\prime}$ & 3.031 .81 & 2.048 & 0.041 \\
\hline Luck plays a big part in determining how soon I will recover from an illness. & $4.061 .61^{\circ}$ & 3.971 .65 & 0.493 & 0.622 \\
\hline Health professionals control my health. & $4.601 .61^{\prime}$ & 4.821 .23 & 1.204 & 0.231 \\
\hline My good health is largely a matter of good fortune. & 3.991 .72 & 3.981 .65 & 0.066 & 0.948 \\
\hline The main thing which affects my health is what I myself do. & 4.441 .30 & 4.411 .38 & 0.203 & 0.839 \\
\hline If I take care of myself, I can avoid illness. & 4.351 .17 & 4.431 .41 & 0.597 & 0.551 \\
\hline
\end{tabular}

Whenever I recover from an illness, it's usually because other people (for example, doctors, nurses, family, friends) have been taking good care of me.

No matter what I do, I 'm likely to get sick.

4.421 .3544 .521 .4620 .6370 .525

If it's meant to be, I will stay healthy.

3.111 .8663 .321 .8200 .9830 .326

If I take the right actions, I can stay healthy.

4.491 .5284 .241 .6341 .3410 .181

4.581 .3394 .591 .2610 .0790 .937

Regarding my health, I can only do what my doctor tells me to do.

4.581 .4994 .541 .3880 .2670 .789

MHLC (B)

Admission to

hospital

Early Delayed $t \quad p$

$\overline{\mathrm{X}}$ SD $\mathrm{X}$ SD

If I become sick, I have the power to make myself well again.

2.821 .7133 .051 .7071 .1570 .248

Often I feel that no matter what I do, if I am going to get sick, I will get sick.

3.811 .7393 .681 .6880 .6290 .530

If I see an excellent doctor regularly, I am less likely to have health problems.

3.841 .4124 .191 .5072 .0310 .043

It seems that my health is greatly influenced by accidental happenings.

3.591 .5593 .511 .5690 .4420 .659

I can only maintain my health by consulting health professionals.

I am directly responsible for my health.

Other people play a big part in whether I stay healthy or become sick.

Whatever goes wrong with my health is my own fault.

When I am sick, I just have to let nature run its course.

Health professionals keep me healthy.

When I stay healthy, I'm just plain lucky.

My physical well-being depends on how well I take care of myself.

4.261 .4524 .441 .3391 .1600 .247

$\begin{array}{lllllll}4.33 & 1.398 & 4.46 & 1.371 & 0.808 & 0.420\end{array}$

$\begin{array}{lllllll}3.27 & 1.672 & 3.49 & 1.668 & 1.135 & 0.257\end{array}$

$\begin{array}{llllll}3.11 & 1.710 & 3.39 & 1.746 & 1.394 & 0.164\end{array}$

$\begin{array}{lllllll}3.22 & 1.875 & 3.10 & 1.834 & 0.558 & 0.577\end{array}$

4.341 .4434 .481 .3550 .9090 .364

$4.181 .5423 .981 .726 \quad 1.0400 .299$

$\begin{array}{llllll}4.79 & 1.151 & 4.64 & 1.293 & 0.978 & 0.329\end{array}$

When I feel ill, I know it is because I have not been taking care of myself properly.

The type of care I receive from other people is what is responsible for how well I recover from an illness.

Even when I take care of myself, it's easy to get sick.

3.831 .6374 .221 .5782 .1440 .033

4.271 .5444 .251 .4950 .0920 .927

When I become ill, it's a matter of fate.

3.651 .7063 .731 .5770 .4000 .689

I can pretty much stay healthy by taking good care of myself.

3.781 .8813 .691 .7950 .4130 .680

Following doctor's orders to the letter is the best way for me to stay healthy.

4.321 .3364 .551 .2791 .5840 .114

\begin{tabular}{|l|l|l|l|l|l|}
\hline 4.82 & 1.255 & 4.78 & 1.334 & 0.257 & 0.797 \\
\hline
\end{tabular} 
$\operatorname{MHLC}(\mathrm{C})$

Admission to hospital

Early Delayed $t \quad p$

$\overline{\mathrm{X}}$ SD $\quad \overline{\mathrm{X}} \mathrm{SD}$

If my condition worsens, it is my own behavior which determines how soon I will feel better again.

4.381 .2644 .351 .3610 .1720 .864

As to my condition, what will be will be.

3.971 .5763 .951 .5560 .1020 .918

If I see my doctor regularly, I am less likely to have problems with my condition.

Most things that affect my condition happen to me by chance.

4.131 .3974 .321 .4741 .1160 .265

4.011 .3663 .811 .4851 .1650 .245

Whenever my condition worsens, I should consult a medically trained professional.

I am directly responsible for my condition getting better or worse.

Other people play a big role in whether my condition improves, stays the same, or gets worse.

Whatever goes wrong with my condition is my own fault.

Luck plays a big part in determining how my condition improves.

In order for my condition to improve, it is up to other people to see that the right things happen.

4.761 .3474 .951 .2181 .3700 .171

3.771 .6363 .891 .5940 .6620 .509

Whatever improvement occurs with my condition is largely a matter of good fortune.

The main thing which affects my condition is what I myself do.

3.811 .5243 .791 .5270 .1090 .914

3.071 .7783 .221 .7500 .7430 .458

3.981 .5793 .801 .5451 .0140 .311

3.641 .7373 .761 .6090 .6360 .525

3.841 .7273 .881 .5950 .2390 .811

4.381 .3964 .341 .3870 .2270 .821

I deserve the credit when my condition improves and the blame when it gets worse. 3.471 .8683 .531 .7710 .2960 .767

Following doctor's orders to the letter is the best way to keep my condition from

getting any worse.

If my condition worsens, it's a matter of fate.

4.791 .2624 .721 .3900 .4280 .669

If I am lucky, my condition will get better.

4.031 .6963 .941 .6380 .4500 .653

4.101 .7504 .151 .5570 .2620 .794

If my condition takes a turn for the worse, it is because I have not been taking proper care of myself.

3.781 .7623 .791 .6560 .0920 .927

The type of help I receive from other people determines how soon my condition improves.

4.421 .3084 .241 .5021 .0580 .291

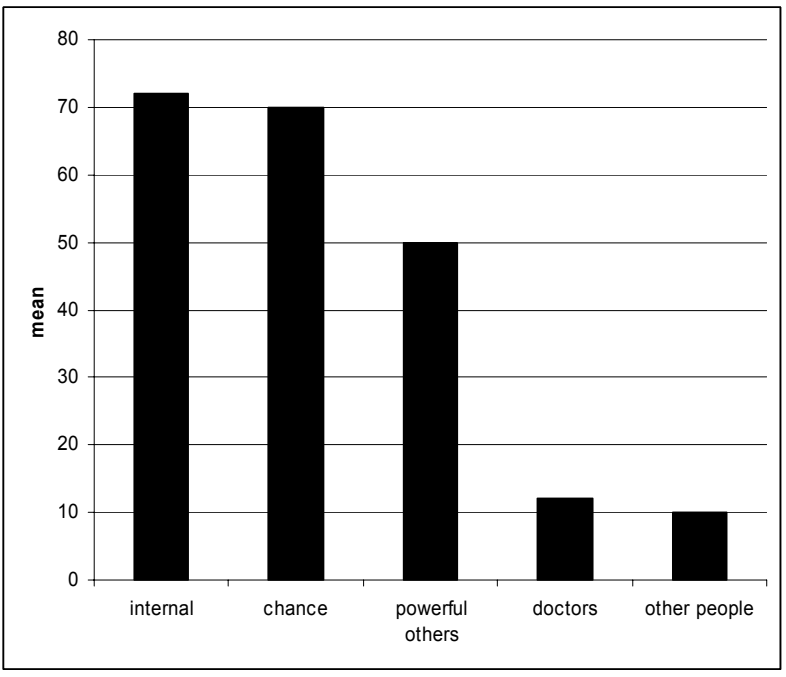

Figure 1. Results obtained from the MHLC scales

\section{Depression in breast cancer patients}

One of the specific aims of this study is to determine the degree of depression in hospitalized patients with malignant breast cancer and the relationship to other factors. In accordance with the HDRS scores, the results show that $59.7 \%$ of respondents do not have any level of depression, $26.2 \%$ have mild depression, $6.9 \%$ have moderate depression, $1.7 \%$ have severe depression, and $5.4 \%$ have profound depression (Figure 2).

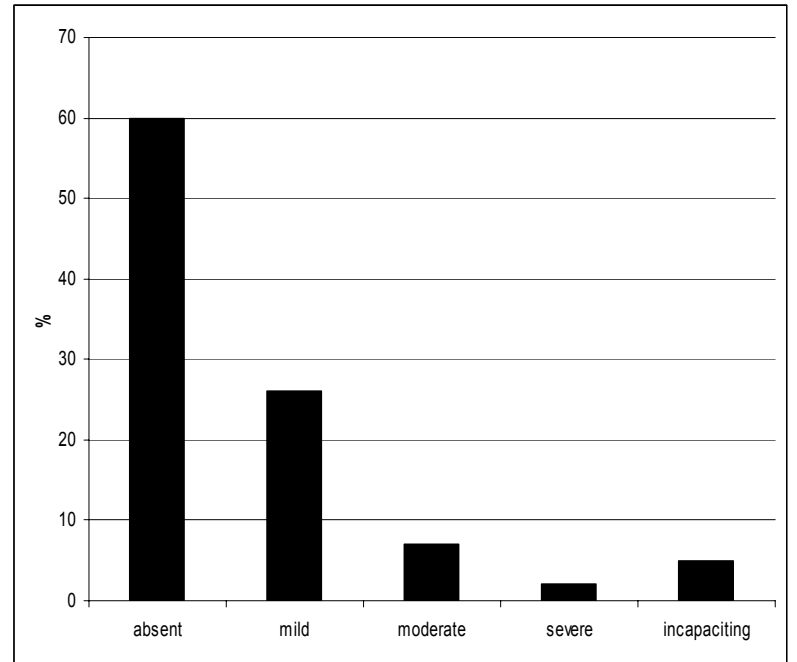

Figure 2. Results obtained from the HDRS scale

The analysis of differences in sociodemographic variables of the respondents according to the obtained results on the HDRS are shown in Table 3.

There is no statistically significant difference between early and late arrival at diagnosis, age, place of residence, education level, and marital status, except for the statistical significance of the respondents' employment status and a high degree of depression $(\mathrm{p}=0.007)$. 
Table 3. Differences in sociodemographic variables of subjects regarding results obtained from the HDRS scale

\begin{tabular}{|c|c|c|c|c|c|c|c|c|c|c|c|}
\hline & \multicolumn{9}{|c|}{ Depression (HDRS 17) } & \multirow{3}{*}{$\chi^{2}$} & \multirow{3}{*}{$\mathrm{p}$} \\
\hline & \multicolumn{2}{|c|}{ Absent } & \multicolumn{2}{|c|}{ Mild } & \multicolumn{2}{|c|}{ Moderate } & \multirow{2}{*}{$\begin{array}{l}\text { Severe } \\
\mathrm{n} \%\end{array}$} & \multicolumn{2}{|c|}{ Incapacitating } & & \\
\hline & $\mathrm{n}$ & $\%$ & $\mathrm{n}$ & $\%$ & $\mathrm{n}$ & $\%$ & & $\mathrm{n}$ & $\%$ & & \\
\hline Admission to hospital & & & & & & & & & & 5.509 & 0.239 \\
\hline Delay & 58 & 24.2 & 28 & 26.4 & 10 & 35.7 & 00.0 & 8 & 36.4 & & \\
\hline Early & 182 & 75.8 & 78 & 73.6 & 18 & 64.3 & 7100.0 & 14 & 63.6 & & \\
\hline Residence & & & & & & & & & & 7.665 & $0.436^{*}$ \\
\hline Urban & 129 & 53.5 & 48 & 45.3 & 13 & 46.4 & 457.1 & 15 & 68.2 & & \\
\hline Rural & 85 & 35.3 & 44 & 41.5 & 10 & 35.7 & 342.9 & 7 & 31.8 & & \\
\hline Sub-urban & 27 & 11.2 & 14 & 13.2 & 5 & 17.9 & 00.0 & 0 & 0.0 & & \\
\hline Living condition & & & & & & & & & & 11.643 & $0.123 *$ \\
\hline With family & 198 & 82.2 & 95 & 89.6 & 23 & 82.1 & 457.1 & 17 & 77.3 & & \\
\hline Living alone & 40 & 16.6 & 9 & 8.5 & 4 & 14.3 & 342.9 & 5 & 22.7 & & \\
\hline Others & 3 & 1.2 & 2 & 1.9 & 1 & 3.6 & 00.0 & 0 & 0.0 & & \\
\hline Marital status & & & & & & & & & & 10.307 & $0.509 *$ \\
\hline Married & 167 & 69.3 & 80 & 75.5 & 19 & 67.9 & 342.9 & 13 & 59.1 & & \\
\hline Single & 23 & 9.5 & 6 & 5.7 & 2 & 7,1 & 228,6 & 3 & 13,6 & & \\
\hline Widowed & 46 & 19.1 & 17 & 16.0 & 7 & 25,0 & 228,6 & 6 & 27,3 & & \\
\hline Divorced & 5 & 2.1 & 3 & 2.8 & 0 & 0,0 & 00,0 & 0 & 0.0 & & \\
\hline Education & & & & & & & & & & 19.485 & $0.576^{*}$ \\
\hline No qualification & 15 & 6.2 & 12 & 11.3 & 3 & 10.7 & 114.3 & 0 & 0.0 & & \\
\hline Primary school (8 yrs) & 74 & 30.7 & 36 & 34.0 & 10 & 35.7 & 342.9 & 6 & 27.3 & & \\
\hline Secondary school (12 yrs) & 115 & 47.7 & 43 & 40.6 & 11 & 39.3 & 342.9 & 12 & 54.5 & & \\
\hline Higher school (14 yrs) & 16 & 6.6 & 4 & 3.8 & 3 & 10.7 & 00.0 & 3 & 13.6 & & \\
\hline More than 12 yrs & 21 & 8.7 & 10 & 9.4 & 1 & 3.6 & 00.0 & 1 & 4.5 & & \\
\hline Unknown & 0 & 0.0 & 1 & 0.9 & 0 & 0.0 & 00.0 & 0 & 0.0 & & \\
\hline Occupation & & & & & & & & & & 25.092 & $0.007 *$ \\
\hline Employed & 66 & 27.4 & 29 & 27.4 & 3 & 10.7 & 00,0 & 7 & 31.8 & & \\
\hline Unemployed & 61 & 25.3 & 22 & 20.8 & 11 & 39.3 & 114.3 & 0 & 0.0 & & \\
\hline Retirement & 106 & 44.0 & 46 & 43.4 & 12 & 42.9 & 685.7 & 15 & 68.2 & & \\
\hline Others & 8 & 3.3 & 9 & 8.5 & 2 & 7.1 & 00.0 & 0 & 0.0 & & \\
\hline Religious & & & & & & & & & & 1.356 & $0.809 *$ \\
\hline Yes & 230 & 95.4 & 100 & 94.3 & 28 & 100.0 & 7100.0 & 21 & 95.5 & & \\
\hline No & 11 & 4.6 & 6 & 5.7 & 0 & 0.0 & 00.0 & 1 & 4.5 & & \\
\hline
\end{tabular}

Table 4. Predictive values of variables for early attendance at hospital for diagnosis and treatment

\begin{tabular}{llllll}
\hline & $\mathrm{B}$ & $\mathrm{S} . \mathrm{E}$. & Wald & $\mathrm{p}$ & OR $(95 \% \mathrm{CI})$ \\
\hline Living place & -0.206 & 0.264 & 0.612 & 0.434 & $0.814(0.485-1.365)$ \\
Family & 1.113 & 0.434 & 6.585 & 0.010 & $3.043(1.301-7.120)$ \\
Marriage & 1.054 & 0.378 & 7.757 & 0.005 & $0.349(0.166-0.732)$ \\
Education level & -0.133 & 0.370 & 0.128 & 0.720 & $0.876(0.424-1.894)$ \\
Working status & -0.404 & 0.330 & 1.504 & 0.220 & $0.668(0.350-1.274)$ \\
Income level & 0.052 & 0.299 & 0.031 & 0.861 & $1.054(0.586-1.894)$ \\
Believer & -1.120 & 0.551 & 4.135 & 0.042 & $0.326(0.111-0.960)$ \\
Age & -0.013 & 0.012 & 1.179 & 0.277 & $0.987(0.963-1.011)$ \\
MHLC-Internal & -0.018 & 0.012 & 2.172 & 0.141 & $0.982(0.959-1.006)$ \\
MHLC-Chance & 0.010 & 0.008 & 1.515 & 0.218 & $1.010(0.994-1.027)$ \\
MHLC-Powerful Others & -0.005 & 0.019 & 0.071 & 0.789 & $0.995(0.958-1.033)$ \\
MHLC-Doctors & -0.004 & 0.050 & 0.006 & 0.938 & $0.996(0.904-1.098)$ \\
MHLC-Other People & 0.022 & 0.045 & 0.239 & 0.625 & $1.022(0.936-1.117)$ \\
\hline
\end{tabular}

Cox \& Snell $\mathrm{R}^{2}=0.055 ; \quad$ Nagelkerke $\mathrm{R}^{2}=0.082$ : Model: $\chi^{2}=6.576 ; \quad \mathrm{df}=8 ; \mathrm{p}=0.583$ 


\section{Predictors for early or late seeking of diagnosis and treatment among respondents}

Age group, living place, living with family, marital status, educational level, occupation/working status, income level, religious and MHLC scales results were included in the logistic analysis model. Table 4 shows the predictive validity of the sociodemographic, and MHLC variables for early seeking of treatment and diagnosis. After the entry of the variables, the entire model was shown as statistically significant, and, as a whole, explains the variance between $4.4 \%$ and $6.6 \%$ and correctly classifies $75.9 \%$ of cases.

The strongest independent positive predictor for the early seeking of diagnosis and treatment is living with family $(\mathrm{OR}=3.043,95 \% \mathrm{CI}=1.301-7.120)$ and marital status ( $\mathrm{OR}=0.349,95 \% \mathrm{CI}=0.166-0.732)$, while religiosity is a negitve predictor $(\mathrm{OR}=0.326,95 \% \mathrm{CI}=0.111$ 0.960 ). The other variables did not have a statistically significant predictive value.

\section{DISCUSSION}

Considering that determinants that show an increase in the prevalence and incidence of breast cancer in women from FB\&H and in the Herzegovina-Neretva region and considering the recommendation made by the WHO, the Federal Institute for Public Health (in collaboration with cantonal/regional institutes and other healthcare partners as well as civil society) is trying to work intensively on this problem. Because of the decentralized nature of the data collection, which does not provide a realistic picture of the magnitude of the problem, and because of the lack of national strategies against cancer and the lack of a coordinated program at the national level, there is a lack of tracking of activities and the estimation of their effectiveness. Local initiatives on behalf of healthcare workers and active non-governmental organizations do exist, but their effectiveness has not been sufficiently tracked and reported. Because of that, there are no data about the number of calls for screening and women's response to those calls. However, the number of women who are admitted in hospital for treatment in the late stages of the disease in the period of one year ( 305 out of 403 women, or $75.7 \%$ ) indicates that the problem is prevalent. According to data published for Europe, among those with newly-diagnosed cases of breast cancer, two thirds are in the early stage, and one third is in the late stage, with metastasis to distal organs (Ferlay et al. 2010). This is partly the result of national, organized and continuous programs for the targeted testing of risky populations. The results of this study demonstrate the opposite: two thirds of women attend at hospital for late treatment. Before being admitted to hospital for treatment, $39.4 \%$ of respondents underwent mammography screening, while $60.6 \%$ did not. The reasons for this may be related to factors influenced by the demographics and psychosocial characteristics of the respondents, but also to the contextual specificity of the local area where the research was conducted. The WHO indicates that the desired outcome objective (within 5 years) of launching a breast cancer screening program is to achieve more than $70 \%$ coverage of women older than 50 years with mammography screening every 2 years. Even though there are no reliable indicators on the number of women covered by the mammography screening program in the Herzegovina-Neretva region, and since two thirds of women in this study are admitted to hospital for diagnosis and treatment in the late stage, this study shows that the participation rates are far lower than the WHO desired goal, and are lower than those found in other countries.

The experiences of the neighboring state of the Republic of Croatia, which has a higher level of healthcare service and long-standing experience organizing and implementing a national program for the prevention and early detection of cancer as well as maintaining a cancer registry, demonstrated that the response of women to calls for mammography in the first cycle were satisfactory (63\%), and decreased in subsequent cycles (Ministry for Health and Social Care of the Republic of Croatia 2006, Šupe Parun 2011). Due to a longlasting economic transition, the basic conditions for such a program in the Herzegovina-Neretva region are lacking because of insufficient funds, an insufficient number of mammographs and trained professionals. In this region of 224,652 inhabitants, among which 123,327 (or 55\%) are women, there are four mammographs located in health centers. This hinders the fulfillment of the healthcare needs of women, even when they are highly motivated to attend screening (Celaya et al. 2010). According to observations by healthcare practitioners in the Oncology Clinic at the University Hospital in Mostar, the number of women who come from individual municipalities varies, which could indicate either a higher incidence and prevalence in individual local communities, but also the insufficient administration and/or an insufficient response to breast examinations in certain areas. Along with this, the large number of women who attended at the clinic in the late stages of the disease could be due to the large distance to the healthcare center where the mammography screening is administered, considering the large geographical dispersion of the population in the area. Supporting this view is the fact that in this study, $11.4 \%$ of women live more than $5 \mathrm{~km}$ from the clinic, while $36.9 \%$ live more than $50 \mathrm{~km}$ away. The large distance is certainly a factor which increases the number of women who do not respond to calls for examination. The authors note that accessibility to healthcare is the strongest predictor of screening (Halpern et al. 2008). 
Along with the problems of organizing and implementing healthcare, the low socioeconomic standards in the region where the study was conducted could be one of the factors in the delay of hospital diagnosis and treatment. According to Akinyemiju report, significant determinants of cancer screening were household SES, rural residence, country health expenditure (as a percent of GDP) as well as healthcare access (Akinyemiju 2012). Badur et al. documented a relationship between low socioeconomic status and/or limited cancer knowledge and low breast cancer screening participation as well as delayed breast cancer detection, despite easy accessibility to screening mammography (Badur et al. 2014). In a large population-based series of breast cancer patients, Downing et al. studied socioeconomic factors in relation to clinical parameters. Their results revealed that living in a more deprived area was associated with increased likelihood of being diagnosed with advanced stage of disease and receiving radiotherapy (Dowing et al. 2007). Furthermore, Banks et al. showed that women who attend the national Health Service Breast Screening Programme come from less deprived areas than non-attenders (Banks et al. 2002). The authors also observed statistically significant correlations between women from different areas of living, which can be explained by poor access to oncologists for women living in rural areas and small towns, compared with patients from cities.

According to the results of this study, the majority of respondents have monthly incomes higher than 300 BAM (1BAM approximately 0,5 EUR). Although there were no statistically significant differences in SES among the two groups of respondents in this study $(p=0.591)$, nor was SES was a statistically significant predictor of early admittance to hospital for diagnosis and treatment $(\mathrm{OR}=1.054 ; 95 \% \mathrm{CI}=0.586-1.894)$, the results should be taken with caution. In fact, among all the respondents, only 17 (or $4.2 \%$ ) have a monthly income lower than $150 \mathrm{BAM}$, which is lower than the $15 \%$ of the total population of FB\&H who have a monthly income of less than 150 BAM, which is considered below the poverty line (Public Health Institute of FB\&H 2010).

Among the socio-economic status, some of the other factors were considered in this study: age, place of residence (urban or rural areas), close social support network (living with family), marital status, education level, employment status, and religiosity. The obtained results show similarities as well as differences compared to other studies.

Statistically significant factors that have an impact on the early attendance at hospital are employment status $(p=0.035)$ and previous mammography $(p=0.036)$, while multivariance analysis indicates that the most important predictors of early attendance at hospital for diagnosis are marital status/marriage $(\mathrm{OR}=0.349,95 \% \mathrm{CI}=0.166-0.732)$, living with family $(\mathrm{OR}=3.043,95 \% \mathrm{CI}=1.301-7.120)$ and non-religiosity $(\mathrm{OR}=0.326,95 \% \mathrm{CI}=0.111-0.960)$.
In sociological and economic studies, it is emphasized that not only is employment the most important determinant of status, but it is also important for creation of meaning, income, social stability, and quality of life, as well as participation in society (McKee-Ryan et al. 2005). Unfortunately, in FB\&H, as in many other transitioning countries, many people are unemployed or underemployed and are exposed to economic poverty and social exclusion (Public Health Institute of the FB\&H 2010). The unemployment rate for 2009 was high (44\%). According to data from the Federal Institute of Public Health, research shows that unemployed persons face difficulties in financial, psychological, physical, and social aspects. Furthermore, their psychological well-being is considerably lower than that of the general population. Although research in other countries shows similar trends, multivariance analysis did not show employment as a predictor of early attendance at hospital.

In this study, a very strong positive predictive value for early attendance for diagnosis and treatment was living with family and marital status. Married patients $(69.8 \%)$ attended earlier for diagnosis and treatment of breast cancer. Other studies researched the effects of marital status and its impact on diagnosis, treatment, and survival for cancer patients, as well as lower survival rates among the unmarried (Neale at al. 1986, James \& Anderson 1999, Goodwin et al. 1987; Ayal et al. 2013). Also, married women tend to have higher life satisfaction due to family living, and partners who take part in the decision-making process. In a meta-analysis conducted by Nelson et al., marital status was not related to delayed attendance at hospital for treatment (Nelson et al. 2016).

In spite of numerous studies indicating the beneficial effects of religiosity on personal health, there are studies noting its negative effects on physical and mental health, or on the inadequate seeking out of healthcare services (Aukst-Margetić et al. 2005, Moore 2006, Van Ness et al. 2002). Although there has not been any systematic research, some studies do show that doctrines of religious communities could impose certain beliefs which promote social deviance that is detrimental to health (Arndt et al. 2001, Gullate 2006). It is also demonstrated that the participation in religious communities can contribute to or create social pressure, and as such, could eventually have a detrimental effect on health. Mitchell et al. researched whether women's religiosity has an effect on early or delayed attendance at examination in the case when the result of selfexamination was the presentation of papable breast lumps (Mitchell et al. 2002). Their results indicate that the majority of women believe that god works through doctors to cure breast cancer. They labelled this dimension «religious intervention with treatment». In the same study, a smaller number of women expressed the belief that examination by a physician is unnecessary because god can cure breast cancer. This 
dimension was labelled «religious intervention in place of treatment». The first dimension correlated with selfreported mammography but not clinical breast examination. The second dimension correlated strongly with the intention to delay presentation of a selfdiscovered breast lump. The given results indicate the need for further research on the interaction among religion, depression, and cancer.

In addition, a possible reason for such a large percentage of women who delay seeking professional help lies in the factors which influence their individual likelihood for early recognition and seeking of professional help, regardless of the type of cancer. How long a cancer patient takes to present may be influenced by several factors, including the nature of the symptoms, awareness of the significance of the symptoms, perception of personal risk of cancer, and physical, social and psychological barriers to health care (Ramirez et al. 1999, Macleod et al. 2009). Forbes et al. reported that in their study twenty-eight percent of participants had not recognized symptoms as serious and this was associated with a doubling in risk of delay. Embarrassment, worry about what the doctor might find, being too busy to go to the doctor and worry about wasting the doctor's time were also strong risk factors for delay, but were much less commonly reported (Forbes et al. 2014). However, there is no evidence to explain fully why some cancer patients delay symptomatic presentation (Austoker et al. 2009, Athey et al. 2011).

The results of this study demonstrate that age is not a predictor of early attendance $(\mathrm{OR}=0.987,95 \%$ $\mathrm{CI}=0.963-1.011)$. In a meta-analysis of 23 studies researching the relationship between advanced age and delayed attendance at hospital, it is observed that there is a big difference between advanced age and delayed attendance for treatment (Nelson et al. 2016).

This study did not confirm the connection between the level of education of women with early admittance for treatment $(\mathrm{OR}=8.876,95 \% \quad \mathrm{CI}=0.424-01.894)$. According to earlier studies, the connection between education and early admittance remains a challenge. The non-attendance of those with lower levels of education is attributed to a lack of understanding of the information they are given, but this is controversial because those with a higher level of education are also found in the group of those who do not respond to organized calls for screening. One explanation may be that those women with a higher level of education attend private clinics for mammography more frequently. It is also possible that they have more demanding jobs and therefore no time for examination. However, this can also be attributed to other psychological and emotional reasons. For example, a study undertaken in Sweden reveals that women who do not believe they will get cancer, those who fear mammography, those who skip mammography, those who do not show an interest, and those who fear radiation from mammography are difficult to influence
(Thurfjell \& Lingrewn 1994). That is to say, that those women will always refuse mammography, whereas those who merely forget to attend can be influenced with education. Other studies also point to the problematic relationship between education and health behaviour. For example, fatalistic beliefs and doubt regarding the benefits of early diagnosis are more common among those with a lower SES, which can be, but is not necessarily, related to level of education (Niederdeppe \& Levy 2007, Wardle et al. 2004). The question is whether or not a general level of education could be a significant predictor, especially in the population of $\mathrm{FB} \& \mathrm{H}$, where $77.4 \%$ of women have a low level of education (Institute for Statistics FB\&H 2014) or whether the answer lies elsewhere. More and more research indicates the need to research health literacy as a predictor of health behaviour which does not necessarily correspond to the level of formal education (Rabia et al. 2008).

According to the aim of this study, special attention was done to examine the health beliefs and behaviors of respondents. Out of numerous models explaining health behaviour, the authors of this study have chosen the health locus of control, using the Multiudimensional Health Locus of Control (MHLC) scales. MHLC has been applied in several research on women with breast cancer screening behaviours (Rowe et al. 2005) individuals' knowledge of breast cancer and adjustment (Bettencourt et al. 2008). They have also been studies of delay to breast cancer treatment (Mohamed et al. 2005). Nemcek found that women who strongly believed that health professionals controlled their health were less likely to adhere to recommended guidelines for breast self-examination (Nemeck 1989). By studying the relationship between health beliefs, health locus of control, and women's mammography behaviour, Holm et al. established that there is partial support for the Health Belief Model and no support for locus of control (i.e. MHLC was not associated with mammography screening) (Holm et al. 1999). This study also failed to show a statistically significant predictive power of the MHLC scale on the early attendance at hospital for treatment for women with breast cancer. In contrast to this, other authors have found a strong positive relationship between health locus of control and intent to undergo mammography screening (Wehrwein \& Eddy 1993).

By researching the connection between health locus of control and assimilation of cancer information, Wang et al. established that women's Internal locus of control did not significantly predict greater cancer knowledge and does not appear to be a characteristic that must be considered when creating women's cancer education programs (Wang et al. 2010). The authors emphasized that «MHLC (were) never intended to be used by themselves, they were intended to moderate be moderated by other theoretically relevant variables such as health value, other expectancies or disease severity». 
However, in this study, MHLC scales were not a statistically significant predictor of early admittance to hospital and more research is needed to test this construct before any conclusions about its value can be drawn.

The results of this study demonstrate that $60 \%$ of women who were hospitalized at the Clinical Hospital in Mostar for diagnosis and treatment of breast cancer do not have signs of depression according to the HDRS measure, and the impact of depression is not related to late or early arrival at hospital for diagnosis and treatment. This result is different from those results obtained in similar research. For example, studies conducted in the same clinic in 2012 among oncology patients, regardless of the location of the primary tumor, determined a more significant presence of depression (54\%), especially among those of a younger age (Vukojević et al. 2012). Other research on depression among women diagnosed with breast cancer determined a higher percentage of women with depressive symptoms (57\%) (Tojal \& Costa 2015). One possible reason for the lower depression among patients in this research is the non-recognition of depression when only the HDRS is used. The results of this research do not indicate a relationship between depression and time of arrival at hospital and sociodemongraphic characteristics of the respondents, except for the relationship between depression and employment status. In contrast, Fujisawa et al. indicate that depression is a significant predictor of lower health utility value, which could be related to late diagnosis of breast cancer (Fujisawa et al. 2016), while Toyal and Costa determined that depression in breast cancer patients is related education and marital status (Tojal \& Costa 2015). In contrast to the commonly held belief that depression and psychological factors predict breast cancer, Aro et al. did not confirm this in their longitudinal study (Aro et al. 2005), and an epidemiological study conducted by Butow et al. did not establish the influence of social support, anxiety and depression on cancer development (Butow et al. 2000).

\section{Limitations}

This study had several limitations. The first limitation is the choice of factors related to delayed or early attendance at hospital for diagnosis and treatment. The list of potential factors capable of influence is very broad but did not include certain motivational factors such as positive family history and risk-factors related to individual anamnesis. In addition, lifestyle habits and social environment (for example, health and illness beliefs in the community as part of tradition and culture) were not analyzed. There was also no consideration for predictors related to the seeking of healthcare (frequency of visits to family doctor, hospital stay, etc.) The second limitation is that the only measure used to establish the likelihood of early or delayed attendance at hospital was the MHLC, and no other models (such as the Health Belief Model) were used. The research was conducted among individuals who have already been diagnosed with a particular health condition. It remains to be seen whether MHLC results would be the same in the general population, in order to improve communitybased prevention efforts. Another limitation of the study is that only the HDRS was used to determine the level of depression. There was no anamnestic data or data about medication use and psychosocial support. Despite these limitations, the advantage of this study is in its use of the TNM classification system for determining the stage of the disease as an objective indicator or early or delayed attendance at hospital as well as the possibility of the application of the Bosnian version of the MHLC and HDRS scales.

\section{CONCLUSION}

The fact that two thirds of patients with breast cancer come late for diagnosis and treatment indicates a serious problem in primary and secondary prevention in the Herzegovina-Neretva region. In addition to providing the basic conditions for the program in the community, which are related to financial and human resources, it is important to research the predictors influencing the quality of the implementation of the program. Research has shown that early attendance at hospital for treatment is influenced by previous attendance at mammography screening and employment status; marital status and living with family were also indicated as important predictors. It is established that religiosity is a negative predictor. Although health locus of control was not a statistically significant predictor of early attendance at hospital, the recommendation is that further research focus on the implementation of the MHLC scales in the community. The Bosnian version of the MHLC and HDRS scales may give health professionals a perspective on the beliefs of cancerinfected individuals concerning health locus of control and help determine the degree of depression in breast cancer patients. This knowledge could be useful in planning appropriate and specific interventions, not only because of early diagnosis but also to ensure good mental health and resilient behaviour. This study shows challenges, as well as the need for further research on the predictors of the delayed seeking of treatment and diagnosis in breast cancer patients, as well as those predictors that could affect the further course of treatment and quality of life.

\section{Acknowledgements: None.}

Conflict of interest: None to declare. 


\section{Contribution of individual authors:}

Gordana Pavlekovic and Inga Marijanovic participated in the design of the study, the study of results, analysis, interpretation of data;

Marko Martinac statistical data processing;

Teo Buhovac search literature.

\section{References}

1. Akinyemiju TF: Socio-Economic and Health Access Determinants of Breast and Cervical Cancer Screening in LowIncome Countries: Analysis of the World Health Survey. PLoS One 2012; 7:e48834. Published online 2012 Nov 14. Available from: www.ncbi.nlm.nih.gov/pubmed/23155413. Accessed December 15, 2015.

2. Aro AR, De Koning HJ, Schreck M, Henriksson M, Anttila A, Pukkala E. Psychological risk factors of incidence of breast cancer: a prospective cohort study in Finland. Psychol Med 2005; 35:1515-21.

3. Atndt V, Sturmer T, Stegmaier Ch, Ziegler H: Sociodemographic factors, health behavior and late-stage diagnosis of breast cancer in Germany. $J f$ Clinical Epidemiology 2001; 54:719-27.

4. Athey VL, Suckling RJ, Tod AM, Walters SJ, Rogers TK: Early diagnosis of lung cancer: evaluation of a community-based social marketing intervention. Thorax 2011; 67:412-17.

5. Aukst-Margetic B, Jakovljevic $M \&$ Margetic $B$ : Depression, cancer and religiosity. Psychiatr Danub 2002; 4:9-18.

6. Aukst-Margetić B, Jakovljević M, Margetić B, Bišćan M, Šamija M: Religiosity, depression and pain in patients with breast cancer. General Hospital Psychiatry 2005, 27:250-5.

7. Austoker J, Bankhead C, Forbes LJL, Atkins L, Martin F, Robb KA et al. Interventions to promote cancer awareness and early presentation: systematic review. $\mathrm{Br} J$ Cancer. 2009; 101:31-9.

8. Ayal AA, Ming-Hui Ch, McCarthy EP, Mendu ML, Koo S, Wilhite TJ et al. Marital status and survival in patients with cancer. J Clin Oncol 2013; 31:3869-76.

9. Badur W, Donizy P, Szełemej J, Kornafel J, Hałon A, Matkowski R: Cancer awareness and socioeconomic status are associated with mammography screening participation and early detection of breast cancer. Family Medicine \& Primary Care Review 2014; 4:329-32.

10. Ballenger JC, Davidson JRT, Lecruiber I, Nutt DJm Jones $R D$, Berard RMF: Consensus statement on depression, anxiety and oncology. J Clin Psychiatry 2001; 62(suppl 8):64-9

11. Banks E, Beral V, Cameron R, Hogg A, Langley $N$, et al.: Comparison of various characteristics of women who do and do not attend for breast cancer screening. Breast Cancer Res 2002; 4:R1.1-R1.6.

12. Bettencourt BA, Talley AE, Molix L et al: Rural and urban breast cancer patients: health locus of control and psychological adjustment. Psychooncology 2008; 17:932-39.

13. Bray F, Ren JS, Masuyer E, Ferlay J: Global estimates of cancer prevalence for 27 sites in the adult population in 2008. Int J Cancer 2013; 132:1133-45.
14. Burgess C, Cornelius V, Love S, Graham J, Richards M, Ramirez A: Depression and anxiety in women with early breast cancer: five year observational cohort study. BMJ 2005;33:702 Available from: http://dx.doi.org/10.1136/bmj.38343.670868.D3. Accessed December 15, 2015.

15. Butow PN, Hiller JE, Price MA, Thackway SV, Kricker A, Tennant CC: Epidemiological evidence for a relationship between life events, coping style, and personality factors in the development of breast cancer. J Psychosom Res 2000; 49:169-81.

16. Celaya MO, Berke EM, Onega TL, Gui J, Riddle BL, Cherala SS et al.: Breast cancer stage at diagnosis and geographic access to mammography screening (New Hampshire, 1998-2004). Rural Remote Health 2010; 10:1361.

17. Christiansen $S$, Zachariae R, Jensen AB et al.: Prevalence and risk of depressive symptoms 3-4 months post-surgery in a nationwide cohort study of Danish women treated for early stage breast-cancer. Breast Cancer Res Treat 2009; 113:339-55

18. Downing A, Prakash K, Gilthorpe MS, Mikeljevic JS, Forman D: Socioeconomic background in relation to stage at diagnosis, treatment and survival in women with breast cancer. Brit J Cancer 2007; 96:836-40.

19. Ferlay J, Soerjomataram I, Ervik M, Dikshit R, Eser S, Mathers $C$ et al.: GLOBOCAN 2012 v1.0, Cancer Incidence and Mortality Worldwide: IARC CancerBase No. 11. Available from: http://globocan.iarc.fr. Accessed December 12, 2015.

20. Forbes LJL, Simon AE, Warburton F, Boniface D, Brain $K E$, Dessaix $A$ et al.: Differences in cancer awareness and beliefs between Australia, Canada, Denmark, Norway, Sweden and the UK (the International Cancer Benchmarking Partnership): do they contribute to differences in cancer survival. Brit J Cancer 2013; 108:292-300.

21. Forbes LJL, Warburton F, Richards MA, Ramirez AJ: Risk factors for delay in symptomatic presentation: a survey of cancer patients. Brit J Cancer 2014; 111:581-88.

22. Fujisawa D, Inoguchi $H$, Shimoda $H$, Yoshiuchi K, Inoue $S$, Ogawa $A$ et al. Impact of depression on health utility value in cancer patients. Journal of the Psychological, Social and Behavioral Dimension of Cancer 2016; 25:491-5.

23. Gabe $R$ \& Duffy $S W$ : Evaluation of service screening mammography in practice: the impact on breast cancer mortality. Ann Oncol 2005; 16:153-62.

24. Gili M, Comas A, Garcia-Garcia M, Monzon S, Antoni SB, Roca M: Comorbidity between common mental disorders and chronic somatic diseases in primary care patients, Gen Hosp Psychiatry 2010; 32:240-5

25. Goodwin JS, Hunt WC, Key RCh, Samet JM. The Effect of Marital Status on Stage, Treatment, and Survival of Cancer Patients. JAMA 1987; 258:3125-30.

26. Grassi L\& Rosti G. Psychiatric and psychosocial concomitants of abnormal illness behaviour in patients with cancer. Psychother Psychosom 1999; 65:246-52.

27. Gullate $M$ : The influence of spirituality and religiosity on breast cancer screening in African American women: application of the Theory of Reasoned Action and Planned Behavior. ABNF J 2006, 17:89-94.

28. Halpern MT, Ward EM, Pavluck AL, Schrag NM, Bian J, Chen AY: Association of insurance status and ethnicity with cancer stage at diagnosis for 12 cancer sites: a retrospective analysis. Lancet Oncol 2008; 9:222-31. 
29. Hamilton M: A rating scale for depression. J Neurol Neurosurg Psychiatry 1960; 23:56-62.

30. Holm CJ, Frank DI, Curtin J: Health beliefs, health locus of control, and women's mammography behavior. Cancer Nurs 1999;22:149-56.

31. International Agency for Research on Cancer: World Cancer Report 2014. World Health Organization, Geneva, 2014.

32. International Agency for Research on Cancer: WHO Classification of Tumours of the Breast. IARC/WHO Classification of Tumours, Geneva, 2012.

33. Institute for Statistics, Federation of Bosnia and Herzegovina: Statistical Yearbook 2014. Sarajevo, 2014.

34. James $C \&$ Anderson K: Marital status, marital satisfaction, and support processes among women at high risk for breast cancer. Journal of Family Psychology 1999; 13:629-41.

35. Kissane DW, Maj M, Sartorius N: Depression and Cancer. Wiley-Blackwell, Chichester, 2011.

36. Lantz PM, Weigers ME, House JS: Education and income differentials in breast and cervical cancer screening. Policy implications for rural women. Med Care 1997; 35:219-36.

37. Macleod U, Mitchell ED, Burgess C, MacDonald S, Ramirez AJ: Risk factors for delayed presentation and referral of symptomatic cancer: evidence for common cancers. Br J Cancer 2009; 101:92-101.

38. Massie MJ: Prevalence of depression in patients with cancer. J Natl Cancer Inst Monogr 2004; 32:57-71.

39. McKee-Ryan FM, Song Z, Wamberg CR, Kinicki AJ: Psychological and physical well being during unemployment: A meta-analytic study. Journal of Applied Psychology 2005; 90: 53-6.

40. Ministry of Health and Social Welfare, Republic of Croatia: Croatian breast cancer screening program "Mamma". Available from: http://www.mzss.hr/hr Iprogrami_i_projekti Accessed January 19, 2015.

41. Mitchell J, Lannin DR, Mathews HF, Swanson MS: Religiuos beliefs and breast cancer screening. $J$ Womens Health 2002;11:907-15.

42. Mohamed IE, Skeel WK, Tamburrino M, Wryobeck J, Carter S. Understanding locally advanced breast cancer: what influences a woman's decision to delay treatment? Prev Med 2005; 41:399-405.

43. Moore RS: Impact of culture, education and socioeconomic status. Breast cancer in women of African descent 2006;313-32.

44. Neale AV, Tilley BC, Vernon SW. Marital status, delay in seeking treatment and survival from breast cancer. Soc Sci Med 1986; 23:305-12.

45. Nelson HN, Fu R, Cantor A, Pappas M, Daeges M, Humphrey L: Effectiveness of breast cancer screening. Systematic review and meta-analysis to update the 2009 U.S. Preventive Services Task Force Recommendation. Ann Intern Med 2016; 164: 244-55.

46. Nemcek MA: Factors influencing black women's breast selfexamination practice. Cancer Nursing 1989; 12:339-43.

47. Niederdeppe $J \&$ Levy AG: Fatalistic beliefs about cancer prevention and three prevention behaviors. Cancer Epidemiol Biomarkers Prev 2007; 16:998-1003.

48. Norsa'adah B, Rahmah MA, Rampal KG, Knight A: Understanding barriers to Malaysian women with breast cancer seeking help. Asian Pac J Cancer Prev 2012, 13:3723-30.
49. Polasek O, Kolcic I, Voncina L, Strnad M, Vuletic S, Kern $J$ : Breast, colon, and prostate screening in the adult population of Croatia: does rural origin matter? Rural Remote Health 2007; 7:749. Available from:

http://www.rrh.org.au. Accessed May 15, 2016.

50. Public Health Institute of the Federation of Bosnia and Herzegovina: Health Statistics Annual. Sarajevo, 2010.

51. Public Health Institute of the Federation of Bosnia and Herzegovina: Health Status and Health Care in FB\&H in 2013. Sarajevo, 2013.

52. Rabia A, Aleyamma $M$, Rajan B: Effects of socioeconomic and demographic factors in delayed reporting and late-stage presentation among patients with breast cancer in a major hospital in South India. APJCP 2008; 9:703-7.

53. Ramirez AJ, Westcombe AM, Burgess CC, Sutton S, Littlejohns P, Richards MA: Factors predicting delayed presentation of symptomatic breast cancer: a systematic review. Lancet 1999; 353:1127-31.

54. Rowe JL, Montgomery GH, Duberstein PR, Bovbjerg DH: Health locus of control and perceived risk for breast cancer in healthy women. Behav Med 2005; 31:33-40.

55. Schueler KM, Chu PW, Smith-Bindman R: Factors associated with mammography utilization: a systematic quantitative review of the literature. $J$ Womens Health 2008; 17:1477-98.

56. Sellick SM \& Crooks DL: Depression and cancer: an appraisal of the literature for prevalence, detection, and practice guideline development for psychological interventions. Psychooncology 1999; 8:315-33.

57. Shafter AB: Meta-analysis of the factor structures of four depression questionnaires: Beck, CES-D, Hamilton, and Zung. J Clin Psychol 2006; 62:123-46.

58. Stamenić $V \&$ Strnad M: Urban-rural differences in a population based breast cancer screening program in Croatia. Croat Med J 2011; 52:76-86.

59. Stewart BW \& Wild CP: World Cancer Report 2014. WHO/IARC Nonserial Publications, 2014. Available from: http://shop.iarc.fr/products/wcr2014. Accessed June 10, 2016.

60. Šupe Parun A: Nacionalni program otkrivanja raka dojke dojke. Available from: http:// www.hcjz.hr. Vol 7, 7. October 2011.

61. Tojal $C \&$ Costa $R$ : Depressive symptoms and mental adjustment in women with breast cancer. Psychooncology 2015; 24:1060-5.

62. Thurfjell EL \& Lindgren JA: Population-based mammography screening in Swedish clinical practice: prevalence and incidence screening in Uppsala County. Radiology 1994; 193:351-7.

63. Van Ness PH, Kasl SV, Jones BA: Are religious women more likely to have breast cancer screening? J Relig Health 2002; 41: 333-46.

64. Vukojević M, Perić I, Kordić M: Anksioznost $i$ depresivnost kod onkoloških bolesnika u Sveučilišnoj kliničkoj bolnici Mostar. Liječ Vjesn 2012; 134:208-14.

65. Wallston KA, Wallston BS, DeVellis R: Development of the multidimensional health locus of control (MHLC) scales. Health Educ Monogr 1978; 6:160-70.

66. Wallston KA: The validity of the Multidimensional Helath Locus of Control Scales. J Health Psychol 2005; 10:623-31.

67. Wang R, Aldridge AA, Malcarne VL, Choe S, Branz P, Sadler GR: Health locus of control and assimilation of 
cervical cancer information in Deaf women. $J$ Cancer Educ 2010; 25:354-9.

68. Wardle J, McCaffery $K$, Nadel M, Atkin $W$ : Socioeconomic differences in cancer screening participation: comparing cognitive and psychosocial explanations. Soc Sci Med 2004; 59:249-61.

69. Wehrwein TC \& Eddy ME: Breast health promotion: behaviors of midlife women. J Holist Nurs 1993; 11:223-36.

70. Williams JW: Standardizing the Hamilton Depression Rating Scale: past, present and future. Eur Arch Psychiatry Clin Neurosci 2001; 251(suppl 2):116.
71. World Health Organization: National cancer control programs: policies and managerial guidelines, 2nd edition. World Health Organization, Geneva, 2002.

72. World Health Organization: Cancer control: knowledge into action: WHO guide for effective programmes. Early detection. World Health Organization, Geneva, 2008.

73. WHO: Global Action Plan on NCDs 2013-2020: The global role of breast carcinoma guideliness for low and middle-income countries. World Health Organization, Geneva, 2013.

\section{Correspondence:}

Inga Marijanović, MD, specialist in Clinical Oncology Oncology Clinic, University Clinical Hospital Mostar Bijeli brijeg bb, 88000 Mostar, Bosnia and Herzegovina E-mail: inga.marijanovic71@gmail.com 